\title{
Research on the reactivation of Syk expression caused by the inhibition of DNA promoter methylation in the lung cancer
}

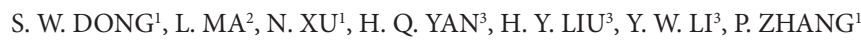 \\ ${ }^{1}$ Department of Cardiothoracic Surgery, Tianjin Medical university General hospital, AnShan Road No.154, Heping district, Tianjin 300052, \\ China, e-mail: lwmsjt@163.com; ${ }^{2}$ Department of Medical Oncology, Tianjin Medical university General hospital, Tianjin, China; ${ }^{3}$ Tianjin Lung \\ Cancer Institute, Tianjin Medical university General hospital, Tianjin, China
}

\section{Received August 18, 2010}

\begin{abstract}
The aim of this study was to study the expression of Syk gene and methylation in its promoter region in the lung cancer and to investigate the relationship between silencing of the Syk gene and DNA methylation of the Syk promoter region in lung cancer cell lines.

Real-time PCR and immunohistochemistry were used to examine the Syk expression in specimens from 3 lung cancer cell lines and 16 lung cancer patients (tumor tissues and adjacent normal tissues). MSP was used to analyze the methylation status of the Syk promoter region. We also investigated the role of restoring Syk expression by using a DNA methyltransferase inhibitor, 5-aza-CdR, in suppressing invasion of lung cancer cell lines.

No expression of the Syk gene was detected in the 3 lung cancer cell lines. In the 16 lung cancer patient samples, Syk expression was significantly lower in the tumor tissues than that in their adjacent normal tissues $(\mathrm{P}<0.05)$. Consistently, immunohistochemistry analysis of Syk protein expression showed that in the lung cancer tissues Syk protein expression was also significantly lower than that in their adjacent normal tissues. In the two lung cancer cell lines (NL9980, YTMLC-9) that lack the endogenous Syk expression, $4 \mathrm{uM}$ demethylation agent 5-aza-CdR treatment was able to reactivate the Syk gene expression, but not NCI-H446.

In conclusion, hypermethylation leads to silencing of the Syk gene in human lung carcinoma cell lines. Methylation of the Syk promoter and loss of Syk expression in lung cancer cell lines are independent biomarkers. Syk may be a potential tumor suppressor in human lung cancer.
\end{abstract}

Key words: 5-aza-2'-deoxycytidine, lung cancer, MSP, promoter methylation, Syk, tumor suppressor gene

Lung cancer is one of the most common malignancies in the world and a leading disease in industrialized countries, including China. Lung cancer development and progression occur through a complex, multistep progress, including oncogene activation, mutation and loss of tumor suppressor genes.

Syk is a potential tumor suppressor gene, whose expression is frequently altered in tumors [1-2]. It is one of the two members of the Syk family (Syk and ZAP-70). Syk was thought to be a hematopoietic cell-specific signaling molecule

Abbreviations: Syk: Spleen tyrosine kinase, MSP: Methylation-specific PCR, 5-aza-CdR: 5-aza-2'-deoxycytidine, DNMT: DNA methyltransferase, Real-time PCR: Real-time quantitative PCR, $g D N A$ : genomic DNA, $d d \mathrm{H}_{2} \mathrm{O}$ : deionized water, NSCLC: nonsmall-cell lung cancer,SCLC: small cell lung cancer and plays an essential role in maturation of lymphocytes and activation of immune cells [3-4]. Recent evidences show that its expression occurs also in many non-hematopoietic cell types. Down-regulation of Syk expression was first observed during breast cancer progression [1]. Its abnormal expression nowadays has also been detected in a number of other types of cancer, such as carcinoma ventriculi [5] and liver cancer [6]. Syk was found to be able to suppress tumorigenesis and metastasis, but the molecular mechanism of the Syk function still remains largely unknown.

DNA methylation has an essential regulatory function in mammalian development, suppressing gene activity by changing chromatin structure[7-8]. It has become apparent that aberrant DNA methylation of promoter region $\mathrm{CpG}$ islands may serve as an alternate mechanism to genetic defects in the inactivation of tumor suppressor genes in human 
malignancies [9-10]. DNA promoter hypermethylation is one of the mechanisms that lead to silencing of cancer suppressor genes. Increasing clinical evidence reveals a positive correlation of reduced Syk expression with increased risk for metastasis, indicating that Syk may be a potential new tumor suppressor[5, 11-13].

Although there is evidence of Syk as a putative tumor suppressor in several cancer types, the role of Syk in lung cancer has not been reported. In the present study, we examined Syk mRNA and protein expression levels in human lung cancer cell lines and primary tissue samples. We also analyzed methylation status of the Syk promoter and its relationship with the Syk mRNA expression in human lung cancer cell lines.

\section{Materials and methods}

Cell lines and tissue samples. Lung cancer cell lines NL9980, YTMLC-9, NCI-H446, and positive, negative controls breast cancer cell lines MCF-7 and MDA-MB-435S were provided by Tianjin Lung Cancer Institute. All cell lines were cultured in recommended media RPMI1640 (GIBCO, HEPES $4.76 \mathrm{~g} / \mathrm{NaCO}_{3} 2.0 \mathrm{~g} / \mathrm{RPMI}-164010.4 \mathrm{~g} / \mathrm{ddH}_{2} \mathrm{O} 1000 \mathrm{~mL}$ ) supplemented with $10 \%$ new-born bovine serum (GIBCO), $1 \times \mathrm{L}$-glutamine and $1 \times$ penicillin-streptomycin at $37^{\circ} \mathrm{C}$ in a humidified incubator with $5 \% \mathrm{CO}_{2}$.

Lung cancer tissues and their matched adjacent noncancerous tissues were obtained from 16 patients with lung cancer undergoing surgical resection in our department. All specimens were placed in liquid nitrogen immediately after resection and stored at $-80^{\circ} \mathrm{C}$ until RNA or genomic DNA extraction. No patient had received chemotherapy or radiation therapy prior to surgery. All patients were confirmed to have lung carcinoma by pathologic test.

The pathological sections of human lung cancer tissues were taken from Tianjin Medical University General Hospital pathology department.

Syk gene expression assay. RNA isolation and reverse transcription reaction. Total cellular and tissues RNA was isolated by using Trizol (Invitrogen) reagent according to the manufacturer's recommendations. Cellular RNA was isolated from $5 \times 10^{6}$ to $1 \times 10^{7}$ cells by $1 \mathrm{ml}$ Trizol decomposition and tissues samples were grounded into a fine powder using a mortar and pestle, incubated in Trizol solution $(100 \mathrm{~g} / \mathrm{L})$ for $15 \mathrm{~min}$. Then $1 / 5$ volume of chloroform was added. After vigorous agitation standing for $5 \mathrm{~min}$, the inorganic phase was separated by centrifugation at $12000 \mathrm{~g}$ for $15 \mathrm{~min}$ at $4^{\circ} \mathrm{C}$, RNA was then precipitated in the presence of equivoluminal of isopropanol and centrifuged at $12000 \mathrm{~g}$ for $10 \mathrm{~min}$ at $4^{\circ} \mathrm{C}$. RNA pellets were washed with $75 \%$ icecold ethanol and centrifuged at $8000 \mathrm{~g}$ for $5 \mathrm{~min}$ at $4^{\circ} \mathrm{C}$ then dissolved in diethypyrocarbonate (DEPC)-treated $\mathrm{H}_{2} \mathrm{O}$. Total RNA quantified and concentration determination using UV spectrophotometer (Beckman Coulter) by absorbency at 260/280 nm and 1.2\% denaturing agarose gel. For Real-time PCR analysis, 2ug RNA was reverse transcribed using Reverse Transcriptase M-MLV (Takara), Ribonuclease inhibitor (Takara) and dNTP mixture (Takara), according to the manufacturer's protocol, the cDNA templates were subjected to PCR amplification.

Real-time PCR. 2.5uL of the resultant cDNA of 3 lung cancer cell lines and 16 pairs of lung cancer and matched adjacent non-cancerous tissues were mixed with $2 \times$ SYBR Premix Ex Taq ${ }^{\mathrm{TM}}$ (Takara). The primer $(5 \mathrm{uM})$ sets used were: Syk, forward 5'-ACTTGGTCAGCGGGTGGAAT-3', reverse 5'-GGGTGCAAGTTCTGGCTCAT-3'; GAPDH, forward 5'AGAAGGCTGGGGCTCATTTGCAGGG-3', reverse 5'GTCACTGGCGTCTTCACCACATG-3'. The amplifications were performed in ABI-7500 Real-time PCR System according to the manufacturer's protocol. Each sample ran in triplicate for each gene. An initial denaturation step was at $95^{\circ} \mathrm{C}$ for $10 \mathrm{~s}$ followed by 40 cycles of denaturation at $95^{\circ} \mathrm{C}$ for $5 \mathrm{~s}$, annealing at $60^{\circ} \mathrm{C}$ for $34 \mathrm{~s}$, then the solubility temperature curve assay was performed. The results of relative quantity were calculated by using $2^{\text {-average } \Delta \Delta C T} \times 100 \%$ method.

Immunohistochemistry. Formalin-fixed, paraffin-embedded sections of lung malignant tumors and adjacent nonneoplastic tissues were subjected to immunostaining with a rabbit polyclonal antibody against Syk c-20 (Santa Cruz). Briefly, 5-uM-thick tissue sections were deparaffinized, rehydrated, and subjected to antigen retrieval by boiling in sodium citrate buffer $(10 \mathrm{mM}, \mathrm{pH}$ 6.0). The sections were incubated at $4^{\circ} \mathrm{C}$ overnight with Syk primary antibody (1:200 dilution, Cell Signaling, Beverly, MA) and then stained with 3,3'-diaminobenzidine. After visualization of immunoreactivity, the sections were counterstained with hematoxylin and mounted. The immunostained sections were evaluated without any knowledge of the patients' clinical information and status of MSP and Real-time PCR of Syk. Normal lung tissues were taken as the internal positive controls. The stains were graded as follows: (a) positive when immunoreactivity is equivalent to that seen in normal lung cells or is moderately decreased; and (b) negative when immunoreactivity is weak or zero.

DNA Methylation analysis. DNA extraction, purification, bisulfite modification and MSP (Mtheylation-specific PCR). Genomic DNA from cell lines or frozen lung cancer tissues was extracted by using a Dneasy kit (Takara). Genomic DNA was treated with methylSEQr ${ }^{\mathrm{TM}}$ Bisulfite Conversion Kit (Applied Biosystems). Briefly, 300ng gDNA was treated with methylSEQr ${ }^{\mathrm{TM}}$ Denaturation Buffer, incubated at $37^{\circ} \mathrm{C}$ for at least $15 \mathrm{~min}$. Then the methylSEQr Conversion Reagent agent was added to each sample, followed by incubation at $50^{\circ} \mathrm{C}$ for 16h. The modified DNA was purified using mehtylSEQr ${ }^{\mathrm{TM}}$ Purification Columns. It was treated again with $\mathrm{NaOH}(0.1 \mathrm{M})$ and precipitated DNA was resuspended in 50uL of TE buffer (3mM Tris (PH8.0)/0.2 mM EDTA)) and subjected to MSP amplification. Methylation-specific primers were designed to cover $9 \mathrm{CpG}$ dinucleotides numbered 17-21 (forward) and 47-50 (reverse). Similarly, unmethylation-specific primers were designed to cover $8 \mathrm{CpG}$ dinucleotides numbered 18-22 
(forward) and 35-37 (reverse). Primers specific for methylation DNA (forward 5'-CGATTTCGCGGGTTTCGTTC-3', reverse 5'-AAAACGAACGCAACGCGAAAC-3'), and unmethylation DNA (forward 5'-ATTTTGTGGGTTTTGTTTGGTG-3', reverse 5'-ACTTCCTTAACACACCCAAAC-3') were added to the same reaction mix for amplification. PCR products were subjected to electrophoresis on a $30 \mathrm{~g} / \mathrm{L}$ agarose gel. The $\mathrm{m}$-specific primer set yielded a band with a size of $243 \mathrm{bp}$ and the un-specific primer set yielded a band with a size of 140bp. PCR conditions were 40 cycles at $94^{\circ} \mathrm{C}$ for 30 s, at $64^{\circ} \mathrm{C}$ for 30 s, and at $72^{\circ} \mathrm{C}$ for $30 \mathrm{~s}$.

Reexpression of the Syk gene by 5-aza-CdR (5-aza-2'-deoxycytidine) treatment. $2 \times 10^{5}$ cancer cells/well were seeded into 6-well plates and treated with 4uM DNA methyltransferase (DNMT) inhibitor: 5-aza-CdR (Sigma) for 3 days. Every day was was used fresh medium containing the drug. After the treatment the cells were incubated with fresh medium without the drug for an additional $48 \mathrm{~h}$ before total RNA was isolated. Real-time PCR was performed as described previously.

\section{Results}

Expression of Syk in lung cancer cell lines and tissues (Fig.1,Tab. 1,2)

Expression of Syk mRNA in 3 lung cancer cell lines by Real-time PCR showed that, all the cell lines had low-level Syk mRNA expression compared to the positive control breast adenocarcinoma cell line MCF-7 or the negative control breast duct cancer cell line MDA-MB-435S. The mRNA expression of Syk gene in all the lung cancer cell lines that we examined were lost $(\mathrm{P}<0.05)$.

Immunohistochemistry (Fig. 2A-F)

Immunohistochemisty results show us: In $\mathrm{SP} \times 100$, the difference between neoplasm and adjacent tissues is exist in every histopathological types. The specific rabbit polyclonal antibody against Syk c-20 is adhere to the cytoplasmic and stained claybank, which is mainly confined to the connective tissue adjacent to cancer, but in the lung cancer part which is absented. In SP $\times 400$, we hardly find the staining sites in all histopathological types.

Table 1. Syk expression in the lung cancer cell lines $(\bar{x} \pm S)$

\begin{tabular}{lccc}
\hline & & \multicolumn{2}{c}{$\mathrm{P}$} \\
\cline { 3 - 4 } Cell lines & & MCF7 & MDA-MB-435S \\
\hline MCF7 & $3479646.090 \pm 224965.900$ & - & 0.005 \\
MDA-MB-435S & $524.707 \pm 46.744$ & 0.005 & - \\
NL9980 & $1493.522 \pm 4.392$ & 0.002 & 0.003 \\
YTMLC-9 & $94.521 \pm 12.564$ & 0.005 & 0.002 \\
NCI-H446 & $24.714 \pm 5.052$ & 0.005 & 0.001 \\
\hline
\end{tabular}

As shown in Table 1, compared with the positive control MCF-7 and negative control MDA-MB-435S, the mRNA expression of Syk gene in all the lung cancer cell lines that we examined were lost $(\mathrm{P}<0.05)$.
A

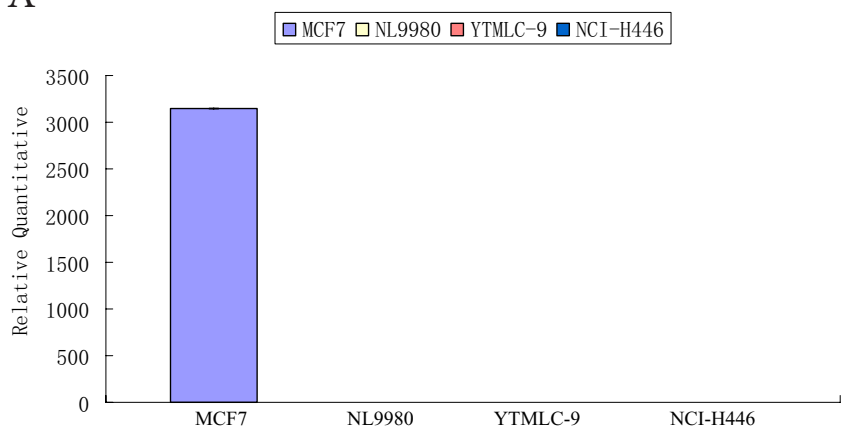

B

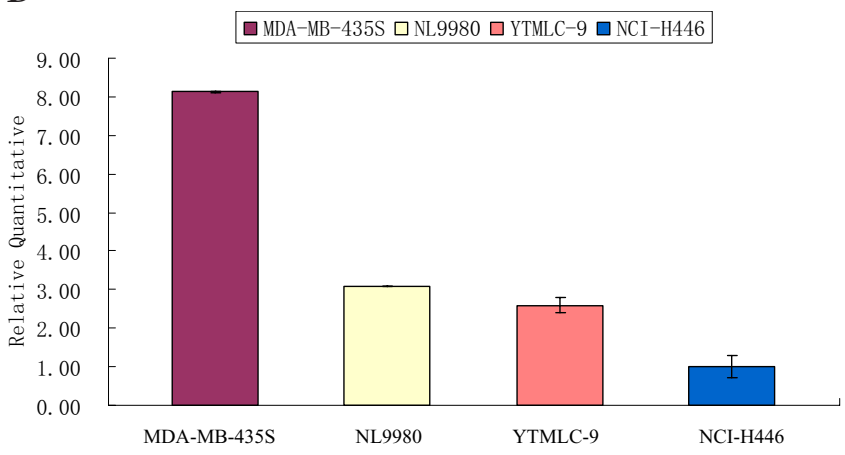

Figure 1. (A) Expression of Syk mRNA in 3 lung cancer cell lines by Realtime PCR showed that, all the cell lines had low-level Syk mRNA expression compared to the positive control breast adenocarcinoma cell line MCF-7. (B) Syk mRNA expression levels were compatible with that of the negative control breast duct cancer cell line MDA-MB-435S.

Table 2. Syk expression in lung cancer tissues $\left(2^{-\Delta \Delta C t}\right)$

\begin{tabular}{|c|c|c|}
\hline No. specimens & Cancer tissues & Normal tissues \\
\hline 1 & 0.865 & 1.093 \\
\hline 2 & 1.860 & 4.836 \\
\hline 3 & 0.237 & 3.335 \\
\hline 4 & 0.456 & 0.419 \\
\hline 5 & 0.377 & 1.205 \\
\hline 6 & 0.613 & 0.573 \\
\hline 7 & 0.597 & 1.429 \\
\hline 8 & 0.309 & 0.901 \\
\hline 9 & 0.464 & 0.631 \\
\hline 10 & 1.077 & 0.702 \\
\hline 11 & 1.432 & 1.780 \\
\hline 12 & 0.693 & 1.727 \\
\hline 13 & 0.655 & 0.728 \\
\hline 14 & 0.541 & 0.906 \\
\hline 15 & 0.477 & 0.726 \\
\hline 16 & 0.515 & 0.238 \\
\hline $\bar{x} \pm S$ & $0.698 \pm 0.429$ & $1.327 \pm 1.192$ \\
\hline $\mathrm{t}$ & \multicolumn{2}{|c|}{-2.47} \\
\hline $\mathrm{P}$ & \multicolumn{2}{|c|}{0.026} \\
\hline
\end{tabular}

As shown in Table 2, in the 16 lung cancer patients, the Syk expression was lower in the tumor tissues than that in their matched adjacent normal tissues $(\mathrm{P}<0.05)$. 
A

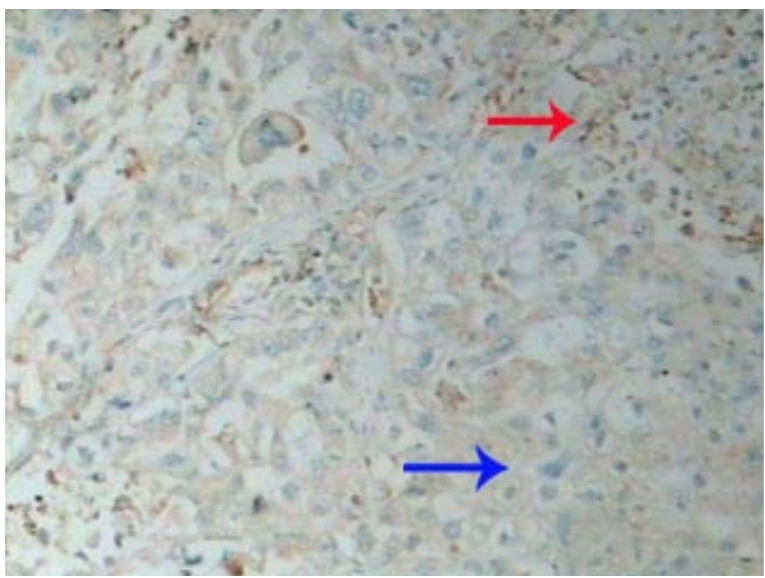

C

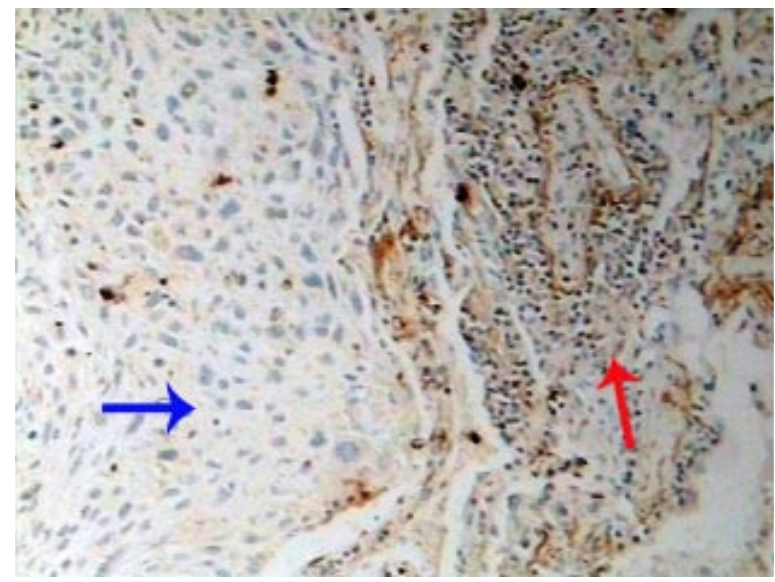

$\mathrm{E}$

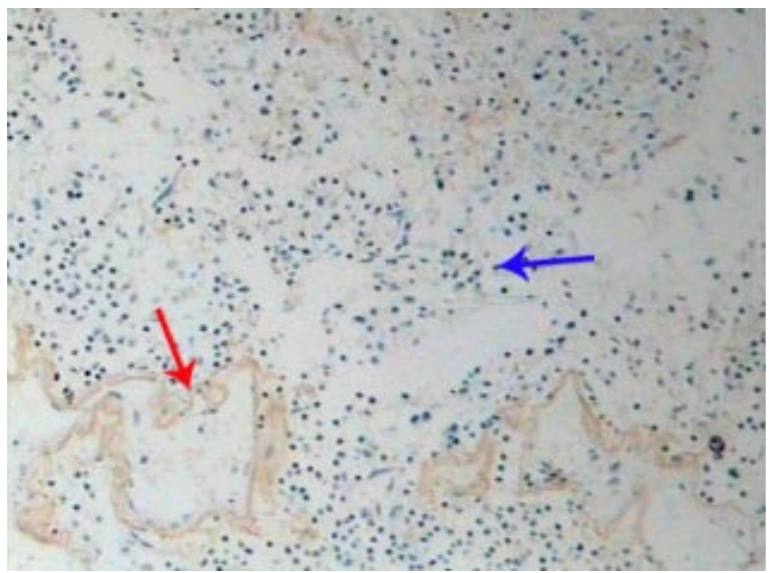

$\mathrm{B}$

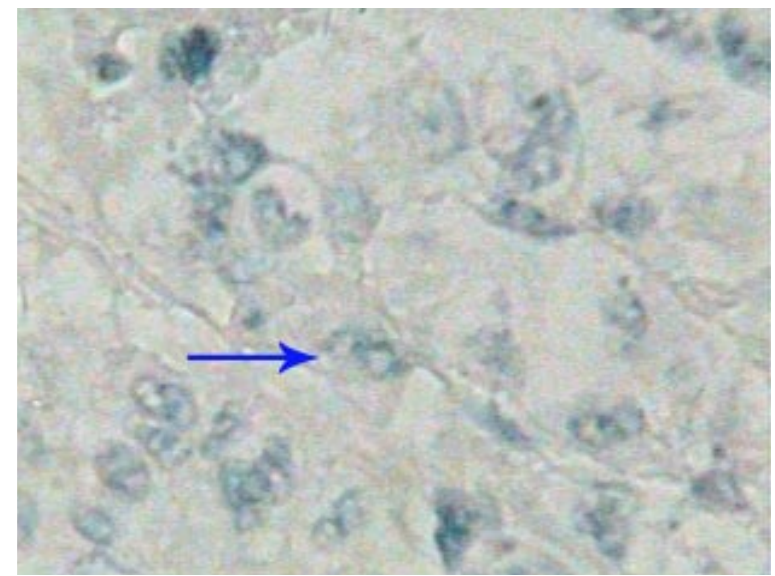

$\mathrm{D}$

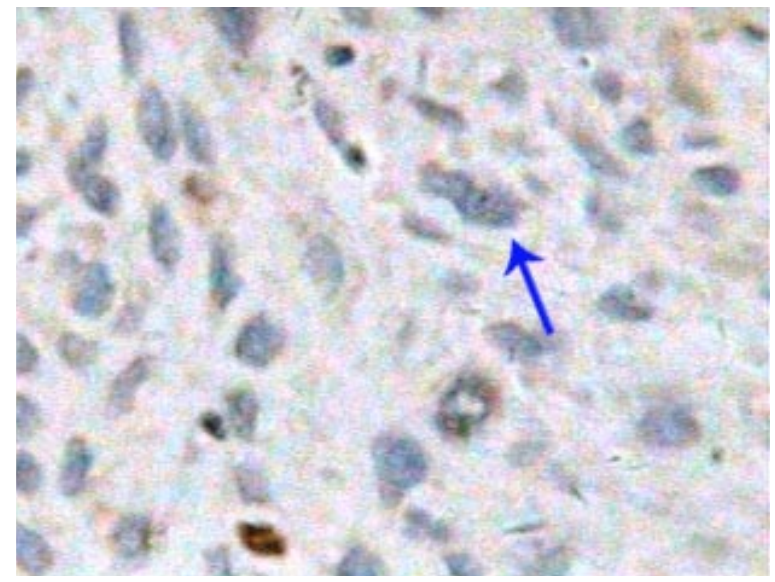

$\mathrm{F}$

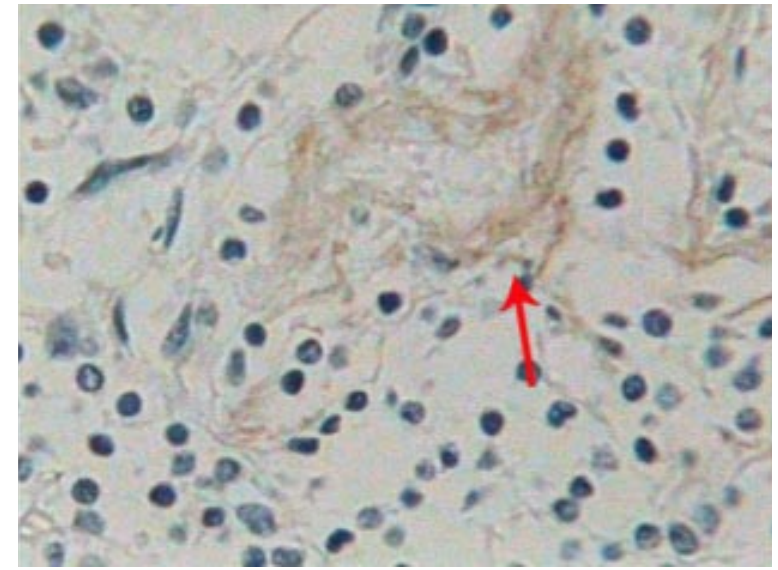

Figure 2. Syk protein expression in lung cancer and adjacent tissues of human large cell lung cancer (A SP $\times 100$, B SP $\times 400$ ), human lung squamous carcinoma $(C S P \times 100, D S P \times 400)$ and human lung small cell carcinoma $(E S P \times 100, F S P \times 400)$. 


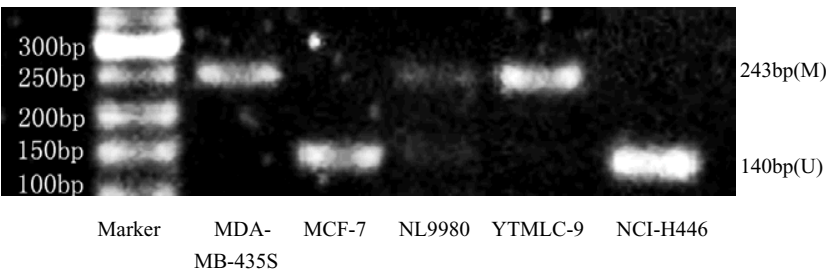

Figure 3. MSP analyses of the Syk promoter methylation status using genomic DNA extracted from 3 lung cancer cell lines, products of 243 and 140bp were expected for methylated $(M)$ and unmethylated (U) DNA, on the side, MDA-MB-435S as methylation positive control and MCF-7 as methylation negative control.

Methylation of the Syk Promoter in lung cancer cell lines (Tab. 3,4, Fig. 3,4)

MSP analyses of the Syk promoter methylation status using genomic DNA extracted from 3 lung cancer cell lines, products of 243 and 140bp were expected for methylated and unmethylated DNA, on the side, MDA-MB-435S as methylation positive control and MCF-7 as methylation negative control. We found that hypermethylation was existed in cell lines NL9980 and YTMLC-9 but not NCI-H446.

Syk negative lung cancer cell lines (NL9980, YTMLC-9 and NCI-H446) were treated with or without 4uM 5-aza-CdR for 3 days. The Syk mRNA expression was examined by Real-time PCR in treated cell lines and compared with that in untreated cell lines. In cell lines NL9980, YTMLC-9 the Syk mRNA expression was up-regulated after the de-methylation drug treatment $(\mathrm{P}<0.05)$, but the Syk mRNA expression in NCI-H446 was approximately the same as that in the control group $(\mathrm{P}>0.05)$.

\section{Discussion}

Syk is a new putative tumor suppressor gene, which constitutes an autonomous family of nonreceptor tyrosine kinases together with zeta-activated protein of $70 \mathrm{kDa}$ (ZAP-70). The locus mapped to chromosome 9 at band q22, contain two adjacent Src homology 2 (SH2) domains and C-terminal kinase domains with two interdomain regions, unlike Srcfamily kinases which lack an SH3 domain[14-16], and which was first recognized as a $40 \mathrm{kDa}$ proteolytic fragment derived from a p72 tyrosine kinase present in porcine spleen[17]. Syk is ubiquitously expressed in hematopoietic cells and has been extensively studied as an effector of B cell receptor (BCR) signaling. It is involved in coupling activated immunoreceptors to downstream signalling events that mediate diverse cellular responses including proliferation, differentiation and phagocytosis. BCR engagement induces signaling cascades mediated by three families of nonreceptor tyrosine kinases: the ZAP-70 family (ZAP-70, Syk), the Src family (Lyn, Fyn, Blk), and the Tec family (Btk, Itk, Etk). After BCR activation, Syk-dependent signaling pathways regulate the clonal expansion, differentiation, or apoptosis of B cells. Phospholipase $\mathrm{C}$ (PLC)-r2 and phosphatidyrlinositol 3-kinase (PI3-K) are

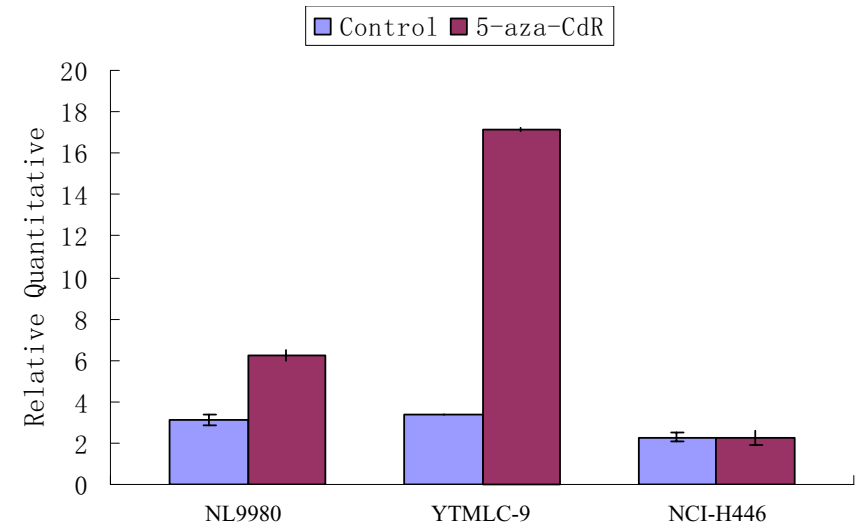

Figure 4. Syk negative lung cancer cell lines (NL9980, YTMLC-9 and NCIH446) were treated with (red bars) or without (blue bars) 4uM 5-aza-CdR for 3 days. The Syk mRNA expression was examined by Real-time PCR in treated cell lines and compared with that in untreated cell lines.

Table 3. 5-aza-CdR treated cell lines than check Syk expression alteration by real-time PCR $(\bar{x} \pm s)$

\begin{tabular}{lccc}
\hline \multirow{2}{*}{ Cell lines } & \multicolumn{2}{c}{$\bar{x} \pm s$} & \multirow{2}{*}{$\mathrm{P}$} \\
\cline { 2 - 3 } & Control & 5-aza-CdR treated & \\
\hline NL9980 & $1.007 \pm 0.172$ & $2.011 \pm 0.227$ & 0.038 \\
YTMLC-9 & $1.000 \pm 0.005$ & $13.948 \pm 1.168$ & 0.004 \\
NCI-H446 & $1.005 \pm 0.138$ & $0.989 \pm 0.100$ & 0.909 \\
\hline
\end{tabular}

As shown in Table 3, in cell lines NL9980 and YTMLC-9, the Syk mRNA expression was up-regulated after the de-methylation drug treatment $(\mathrm{P}<0.05)$, but the Syk mRNA expression in NCI-H446 was approximately the same as that in the control group $(\mathrm{P}>0.05)$.

Table 4. Methylation and expression of the Syk gene in lung cancer cell lines

\begin{tabular}{lcc}
\hline Cell line & Methylation Status & Syk expression \\
\hline NL9980 & M & - \\
YTMLC-9 & M & - \\
NCI-H446 & $\mathrm{U}$ & - \\
\hline
\end{tabular}

M, methylated; U, unmethylated; Positive expression is marked by “+”; Reduced or lack of expression is designated by "-"

key targets of Syk tyrosine phosphorylation after BCR crosslinking. In B cells, Syk phosphorylation of PLC-r2 results in downstream activation of the ERK and kinases, whereas PI3-K phosphorylation by Syk mediates Akt activity Syk also preferentially phosphorylates the a-tubulin subunits of microtubules, which has been proposed to regulate the ability of the microtubule cytoskeleton to function as a scaffold for the assembly of signaling complexes. [18-22]

For the past few years, the researchers discovered that Syk also is a general physiological function in a wide variety of nonhematopoietic cells, and promoter methylation of anti-on- 
cogene is a mechanism for the gene silencing. Syk is expressed in mammary epithelial cells [1], airway epithelial cells[23], human nasal fibroblasts[24], vascular endothelial cells [25], neuron-like cells [26], hepatocytes [27] and melanocytes[28]. The recent identification of Syk as a potent modulator of tumor epithelial cell growth has generated a need for further exploration of the role of nonreceptor tyrosine kinases in wide cancer progression and metastasis. These initial results offer the promise that novel molecular targets may be identified both for the prevention of tumor development and for inhibition of metastatic tumor spread. Some studies reported that Syk is deleted in thelioma tissues.

Cooperman et al. [22] tested the expression of Syk in a panel of well-characterized human breast cancer cell lines. They suggested that loss of Syk mRNA expression may be associated with the progression to a malignant phenotype in breast cancer. Toyama et al. [29] measured Syk mRNA expression in paired samples of primary breast cancer and matched, adjacent non-cancerous tissues by real-time quantitative RTPCR. They found that patients with reduced Syk expression were at significantly increased risk for distant metastasis and showed a significantly poorer prognosis. Yuan et al. [30] is of the opinion that hypermethylation is one of the causes leading to silencing of the Syk gene in human breast cancer. They discovered that $30 \%(6 / 20)$ breast cancer cell lines had hypermethylation in $\mathrm{CpG}$ island of the Syk promoter region, which correlated with silence of the Syk gene. The Syk expression was reactivated after treatment with the de-methylation agent 5-aza-CdR. They also found the Syk promoter methylation in 32\% (12/37) breast cancer tissues but not in adjacent normal tissues. They conclused that Syk as a potential tumor suppressor gene, was silenced in breast cancer and suppressed the tumor invasive level. Similar result was also reported in liver cancer ${ }^{[31]}$. Ding et $\mathrm{a}^{[11]}$ found that Syk expression was low and was associated with its promoter hypermethylation in breast cancer tissues. In addition, the methylation frequency is significantly higher in lymphatic metastasis group than that in lymphatic metastasis negative one. In the study of 61 carcinoma ventriculi patients, Wang $S$ and their colleagues ${ }^{[5]}$ found that Syk expression level is lower and methylation in its promoter is higher in tumor than that in adjacent normal mucosa. Liu et al. [12] also reported the same result. In pre-B cell acute lymphoblastic leukemia, Goodman et al. [13] found that the correlation between loss of Syk expression in mRNA or protein and its promoter hypermethylation was closely related to leukaemia occurrence and evolution.

However, reports on Syk in the field of lung cancer are rare. In our study, we explored the mRNA and protein expression of Syk in lung cancer cell lines, lung cancer and adjacent noncancerous tissues. Our results showed that Syk expression was readily detectable in normal lung tissue and epithelium, but was reduced or absent in the invasive lung tumor cell lines. The level of Syk mRNA expression in lung cancer tissues is significantly lower than that of adjacent noncancerous tissues. Immunohistochemistry of normal and pathologic human breast tissue samples also verified the Syk expression in normal lung epithelium and Syk expression absence in invasive lung carcinomas. Our results indicate that loss of Syk mRNA and protein expression may be correlated to lung tumorigenesis. We also examined methylation status of the $\mathrm{CpG}$ islands in the Syk promoter in lung cancer cell lines, and found hypermethylation in cell lines NL9980 and YTMLC-9. Demethylation is expected to reactivate gene products that are silenced by promoter hypermethylation. When we used a DNMT inhibitor 5-aza-CdR, reactivation of Syk was detected in methylation positive cell lines.

To our surprise, in the experiments we have found some different results in the SCLC NCI-H446 from the other two NSCLC cell lines (NL9980, YTMLC-9). Through the PCR test, we know that the Syk also has the expression diminution in the NCI-H446. However, through the test to the Syk gene promoter methylation, there is no methylation found. This means that the expression diminution of NCI-H446 cell line is not triggered by promoter methylation. The gene mutation, the base deletion, and etc. might be the possible reasons, but the true mechanism needs a further research and discovery. This point of view is consistent with the classification of lung cancer during our clinical experience. In the classification of pathology, the lung cancer cells are often grouped to NSCLS and SCLS. Each of them has its own specific pathology mechanisms, characteristics, staging and treating fashion, one of which is completely different from the other. From the experiment conclusion, we can have the assumption that the gene promoter methylation is an important factor which induces the expression diminution of NSCLC.

Taken together, our findings in lung cancer are in agreement with reports for other types of carcinomas found in the literature $[1,5,11-13,29-31]$. The association of the promoter hypermethylation with the loss or reduction of Syk expression may provide a new way to treat lung cancer.[32-33]

In conclusion, hypermethylation leads to silencing of the Syk gene in human lung carcinoma. Methylation of the Syk promoter and loss of Syk expression in lung cancer are independent biomarkers. Syk may be a potential tumor suppressor in human lung cancer.

Acknowledgement. We thank Prof. Biao He and Dr. Si-cheng Zhao for critically reading the manuscript.

\section{References}

[1] COOPMAN PJ, DO MTH, BARTH M, BOWDEN ET, HAYES AJ et al. The Syk tyrosine kinase suppresses malignant growth of human breast cancer cells. Nature 2000; 406: 742-7. doi: $10.1038 / 35021086$

[2] WANGL, DUKE L,ZHANG PS, ARLINGHAUSRB, SYMMANS WF et al. Alternative splicing disrupts a nuclear localization signal in spleen tyrosine kinase that is required for invasion suppression in breast cancer. Cancer Res 2003; 63: 4724-30.

[3] CHU DH, MORITA CT, WEISS A. The Syk family of protein tyrosine kinases in T-cell activation and development. Immu- 
nol. Rev, 1998; 165: 167-80. doi:10.1111/j.1600-065X.1998. $\underline{\mathrm{tb} 01238 . \mathrm{x}}$

[4] KUROSAKI T. Molecular mechanisms in B cell antigen receptor signaling. Curr Opin . Immunol, 1997, 9: 309-18. doi:10.1016/S0952-7915(97)80075-1

[5] WANG S, DING YB, CHEN GY, XIA JG, WU ZY. Hypermethylation of Syk gene in promoter region associated with oncogenesis and metastasis of gastric carcinoma[J]. World J Gast roenterol 2004; 10: 1815-8.

[6] YUAN Y, WANG J, LI J, WANG L., LI M, YANG Z, ZHANG C., DAI JL. Frequent Epigenetic Inactivation of Spleen Tyrosine Kinase Gene in Human Hepatocellular Carcinoma, Clin Cancer Res, 2006 Nov 15; 12: 6687-95. doi:10.1158/10780432.CCR-06-0921

[7] KASS SU, PRUSS D, WOLFFE AP. How does DNA methylation repress transcription? Trends Genet 1997; 13: 444-9. doi:10.1016/S0168-9525(97)01268-7

[8] RAZIN A, CEDER H. DNA methylation and gene expression. Microbiol Rev 1991; 55: 451-8.

[9] JONES PA, LAIRD PW. Cancer epigenetics comes of age. Nat Genet 1999; 21: 163-7. doi:10.1038/5947

[10] ESTELLER M, CORN PG, BAYLIN SB, HERMAN JG. A gene hypermethylation profile of human cancer. Cancer Res 2001; 61: 3225-9.

[11] DING YB, WU ZY, WANG S, ZHA XM, ZHENG W, et al. Hypermethylation of Syk gene in promoter region is associated with oncogenesis, metastasis of breast carcinoma. Natl Med J China 2004; 84: 290-3.

[12] WANG S, DING YB, CHEN GY, XIA JG, WU ZY. Relationship between hypermethylation of Syk gene in promoter and oncogenesis, metastasis of gastric carcinoma. ACTA Universitatis Medicinalis NanJing (Natural Science) 2006; 26: 169-94.

[13] GOODMAN PA, BURKHARDT N, JURAN B, TIBBLES HE, UCKUN FM. Hypermethylation of the spleen tyrosine kinase promoter in T-lineage acute lymphoblastic leukemia [J]. Oncogene, 2003, 22(16): 2504-14. doi:10.1038/sj.onc.1206313

[14] MUSTELIN T, TASKEN K, Positive and negative regulation of T-cell activation through kinases and phosphatases, Biochem. J. 2003; 37: 15-27. doi:10.1042/BJ20021637

[15] LANIER LL, Natural killer cell receptor signaling, Curr. Opin. Immunol 2003; 15: 308-14. doi:10.1016/S09527915(03)00039-6

[16] SADA K, YAMAMURA H, Protein-tyrosine kinases and adaptor proteins in FcepsilonRI-mediated signaling in mast cells, Curr. Mol. Med 2003; 3: 85-94. doi:10.2174/ $\underline{1566524033361618}$

[17] TANIGUCHI T, KOBAYASHI T, KONDO J, TAKAHASHI K, NAKAMURA $\mathrm{H}$, et al. Molecular cloning of a porcine gene syk that encodes a $72-\mathrm{kDa}$ protein-tyrosine kinase showing high susceptibility to proteolysis[J]. J Biol Chem 1991; 266: 15790-6.

[18] Tohyama Y, Yamamura H, Protein tyrosine kinase, syk: a key player in phagocytic cells. J Biochem 2009; 145: 267-73. doi:10.1093/jb/mvp001

[19] MORTARINO M, GELAIN ME, GIOITA G, CIUSANI E, BAZZOCCHI B. et al. ZAP-70 and Syk expression in canine lymphoid cells and preliminary results on leukaemia cases. Vet
Immunol Immunopathol 2009; 128: 395-401. doi:10.1016/ j.vetimm.2008.12.010

[20] BOELENS J, LUST S, VAN BOCKSTAELE F, VAN GELE M, JANSSENS A, et al. Steroid effects on ZAP-70 and SYK in relation to apoptosis in poor prognosis chronic lymphocytic leukemia. Leuk Res, 2009; 33: 1335-43. doi:10.1016/ j.leukres.2009.02.022

[21] GEAHLEN RL.. Syk and pTyr'd: Signaling through the B cell antigen receptor. Biochim Biophys Acta, 2009; 1793: $1115-27$.

[22] COOPMAN PJ, MUELLER SC. The Syk tyrosine kinase: a new negative regulator in tumor growth and progression. Cancer Lett 2006. Sep 28, 241: 159-73.

[23] ULANOVA M, PUTTAGUNTA L, MARCET-PALACIOS M, DUSZYK M, STEINHOFF U, et al. Syk tyrosine kinase participates in beta1-integrin signaling and inflammatory responses in airway epithelial cells, Am. J. Physiol. Lung Cell. Mol. Physiol 2005; 288: L497-L507. doi:10.1152/ajplung.00246.2004

[24] YAMADA T, FUJIEDA S, YANAGI S, YAMAMURA H, INATOME R, et al. Protein-tyrosine kinase Syk expressed in human nasal fibroblasts and its effect on RANTES production, J. Immunol 2001; 166: 538-43.

[25] INATOME R, YANAGI S, TAKANO S, YAMAMURA $S$ A critical role for Syk in endothelial cell proliferation and migration, Biochem. Biophys. Res. Commun 2001; 286: 195-9. doi:10.1006/bbrc.2001.5355

[26] TSUJIMURA T, YANAGIi S, INATOME R, TAKANO T, ISHIHARA I, et al. Syk protein-tyrosine kinase is involved in neuron-like differentiation of embryonal carcinoma P19 cells. FEBS Lett. 2001; Feb 2; 489: 129-33.

[27] TSUCHIDA S, YANAGI S. INATOME S. DING S, HERMANN P., SUJIMURA T, et al. Purification of a $72-\mathrm{kDa}$ protein-tyrosine kinase from rat liver and its identification as Syk: involvement of Syk in signaling events of hepatocytes, J. Biochem 2000; 127: 321-7.

[28] HOELLER C, THALLINGER C, PRATSHER B, BISTER MD, SCHICHER N, et al. The non-receptor-associated tyrosine kinase Syk is a regulator of metastatic behavior in human melanoma cells, J. Invest 2005; Dermatol 124: 1293-9.

[29] TOYAMA T, IWASE H, YAMASHITA H, HARA Y, OMOTO $Y$, et al. Reduced expression of the Syk gene is correlated with poor prognosis in human breast cancer, Cancer Lett 2003; 189: 97-102. doi:10.1016/S0304-3835(02)00463-9

[30] YUAN Y, MENDEZ R, SAHIN A, DAI JL. Hypermet hylation leads to silencing of the Syk gene in human breast cancer [J]. Cancer Res 2001; 61: 5558-61.

[31] YUAN Y, WANG J, LI J, WANG L, LI M, et al. Frequent epigenetic inactivation of spleen tyrosine kinase gene in human hepatocellular carcinoma. Clin Cancer Res 2006; Nov 15; 12: 6687-95.

[32] BUCHHOLZTA, WAZER DE. Molecular biology and genetics ofbreast cancer development: a clinical perspective. Semin Radiat Oncol 2002; 12: 285-95. doi:10.1053/srao.2002.35248

[33] DING YB, CHEN GY, XIA JG, ZANG XW, YANG HY, YANG L. Correlation of tumor-positive ratio and number of perigastric lymph nodes with prognosis of gastric carcinoma in surgically treated patients. World J Gastroenterol 2004; 10: 182-5. 